\title{
Replacement of metallic parts for polymer composite materials in motorcycle oil pumps
}

\author{
Sandro Donnini Mancini, Antídio de Oliveira Santos Neto, \\ Maria Odila Hilário Cioffi and Eduardo Carlos Bianchi
}

\begin{abstract}
A feasibility study was conducted to determine the use of polyphthalamide/glass-fiber and polyphthalamide/glass-fiber/ polytetrafluoroethylene-based composites as substitutes for aluminum and steel, respectively, in the production of motorcycle oil pump parts (housing, shaft/inner gerotor and outer gerotor). New and used (80,000 km) oil pumps were subjected to performance tests, whose results indicated that the pressure and temperature of the used pump reached a maximum of 1.8 bar and $93^{\circ} \mathrm{C}$, respectively. Thermogravimetric analysis indicated that the materials are stable at the maximum operating temperature, which is $20^{\circ} \mathrm{C}$ lower than the minimum glass transition temperature obtained by dynamic mechanical analysis for both materials at the analyzed frequencies (defined after calculations based on rotations in neutral, medium and high gear). The pressure value was multiplied by a safety factor of at least I.6 (i.e., 3 bar), which was used as input for a finite element analysis of the parts, as well as the elasticity modulus at glass transition temperatures obtained by dynamic mechanical analysis. The finite element analysis indicated that the von Mises stresses to which the composite parts were subjected are 7 to 50 times lower than those the materials can withstand. The results suggest that it is feasible to manufacture motorcycle oil pump parts with these composites.
\end{abstract}

\section{Keywords}

Materials replacement, polymer composite, polyphthalamide, glass-fiber, oil pump

\section{Introduction}

Industries use material replacement to lower costs by reducing the weight of vehicles, and polymer materials are widely employed for this purpose. Fiber-reinforced polymer composites are attractive alternatives, even for applications that traditionally use metallic materials, ${ }^{1-3}$ such as motorcycle oil pumps.

The main function of oil pumps is to inject an adequate flow of oil into parts that need lubrication, according to design specifications. ${ }^{4-6}$ An oil pump usually consists of a housing, rotors, shaft, seal plate, hollow guide pins and screws. Internal gear pumps are considered the most suitable type for motorcycles, particularly gerotor units, whose internal gear (inner gerotor) has one tooth less than the external gear (outer gerotor). ${ }^{4}$ The inner gerotor is responsible for transmitting movement to the outer gerotor, which turns inside the housing. ${ }^{6-8}$
The purpose of this study is to analyze the feasibility of substituting metallic materials (aluminum and steel) for glass-fiber (GF)-reinforced polyphthalamide (PPA), with and without polytetrafluoroethylene (PTFE), in the production of components for motorcycle oil pumps.

The choice of PPA is justified by the fact that the properties of this high-performance thermoplastic render it suitable for applications with strict requirements. ${ }^{9-11}$ Commercial versions of PPA containing relatively large proportions of GFs generally exhibit

UNESP - Universidade Estadual Paulista Sorocaba, Guaratinguetá and Bauru Campus - Brazil

\section{Corresponding author:}

Sandro Donnini Mancini, UNESP - Universidade Estadual Paulista, Av. Três de Março, 5II, CEP: 18087-I80 Sorocaba, SP, Brazil.

Email: mancini@sorocaba.unesp.br 
superior properties and are usually of low cost. ${ }^{3,12,13}$ One of the most interesting properties of these PPA composites is their high maximum working temperatures, ${ }^{11,12,14}$ which are usually higher than those attained in oil pumps, and which most conventional polymers cannot withstand.

PTFE incorporated into a composite is known to improve its wear properties, ${ }^{15-17}$ which is an important consideration for moving parts subjected to friction, such as oil pump shafts.

\section{Experimental}

\section{Design and materials}

Figure 1 depicts details of a current oil pump assembly, with the identification of each component (Figure 1(a)), as well as the proposed new pump (Figure 1(b)). In addition to the materials involved, the main difference between the current and proposed oil pumps is the shaft (part 2, Figure 1(a)), which rotates the inner gerotor (part 3, Figure 1(a)), which is integrated in the proposed pump, as shown in Figure 1(b).

Table 1 describes the materials used in the current and proposed pumps, as well as the function of each part. The tested composites are commercial versions

Table I. Materials used in the current and proposed oil pumps. $^{18-20}$

\begin{tabular}{lcl}
\hline Current material & Proposed material & $\begin{array}{l}\text { Component/ } \\
\text { function }\end{array}$ \\
\hline DIN SINT CII steel & PPA + GF $(30 \%)$ & $\begin{array}{l}\text { Outer gerotor } \\
\text { Inner gerotor }\end{array}$ \\
I6MnCr5 steel & PTFE $(\sim 14 \%)$ & $\begin{array}{l}\text { Shaft } \\
\text { Housing }\end{array}$ \\
\hline
\end{tabular}

PPA: polyphthalamide; GF: glass-fiber; PTFE: polytetrafluoroethylene.

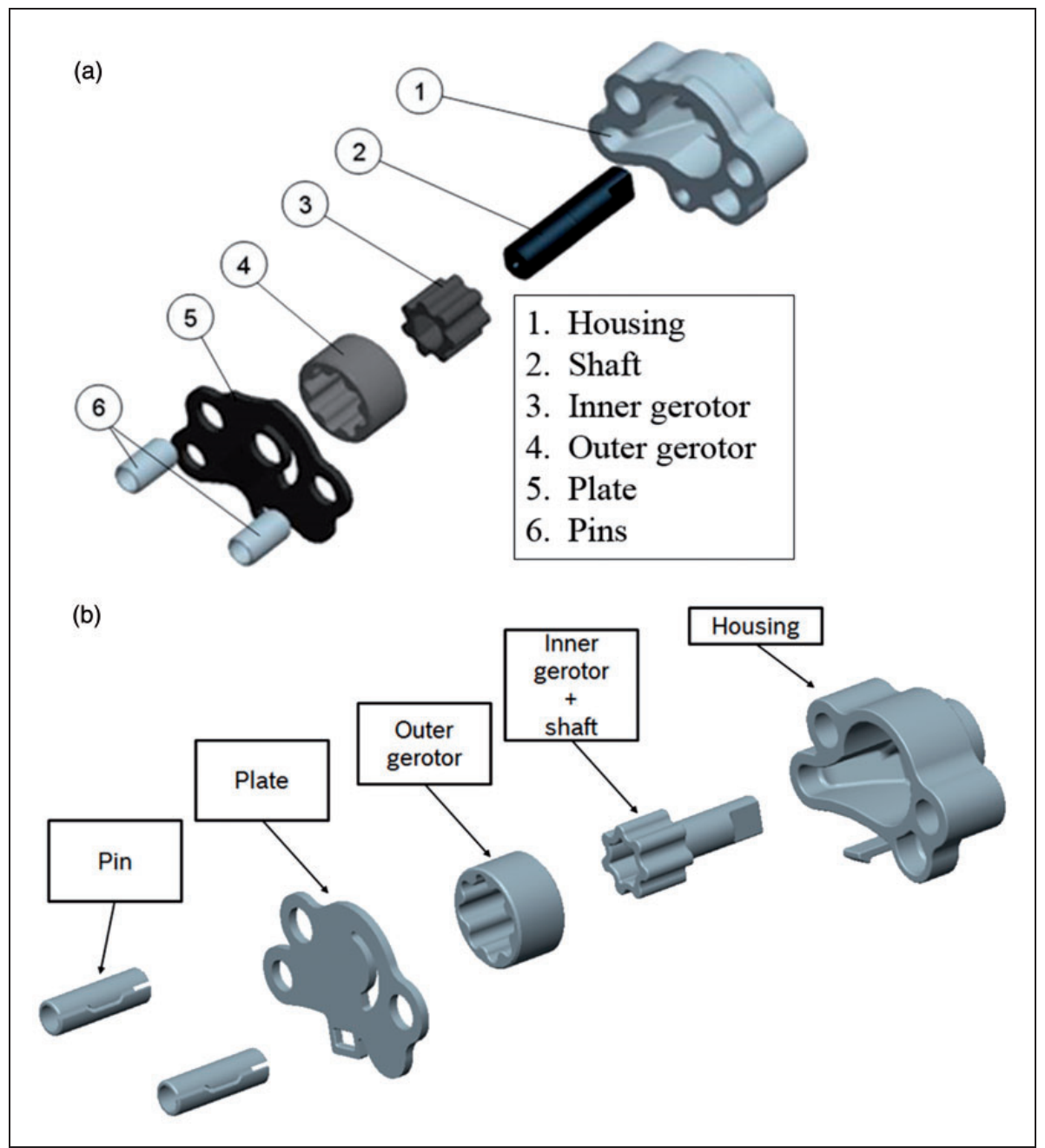

Figure I. Details of the (a) current and (b) proposed oil pumps. 
used in the injection of parts, whose compositions were obtained from a datasheet and from previous studies. ${ }^{18-20}$ The metallic materials were donated by the Schaeffler Group, while the composites were supplied by DuPont Brazil. The materials of the pins (DC04 steel) and plates (SAE 1010) in the current and proposed pumps were the same.

\section{Performance of the current oil pump}

The parameter to determine oil pump performance is dynamic behavior, which is analyzed based on a flow curve on which the pump's rotation and flow rate are monitored. ${ }^{21}$ These curves were obtained by monitoring oil pump pressure, speed, flow rate and temperature in a 150 -cc motorcycle, using the lubricating oil recommended by the manufacturer. A data acquisition system based on HBM Catman/Spider 8 software was used, and the average pressure was calculated during the test.

Tests were conducted with the engine rotation increasing from zero to its maximum of about $11,200 \mathrm{r} / \mathrm{min}$. The drive ratio of this motorcycle is produced by a gear, whose rotation is approximately $5500 \mathrm{r} / \mathrm{min}$.

Oil pressure was monitored at the pump outlet, and temperature was monitored in the crankcase. Rotation was monitored in the cylinder head, where the primary drive shaft of the engine is located. To measure the oil flow rate, the gallery immediately after the oil pump outlet was blocked and a bypass was created by connecting a hose to the output of the cylinder head. The flowmeter was placed between these points and connected in series to a pressure sensor. Due to the limitations of the flow sensor, the data had to be analyzed with the engine idling at $1000 \mathrm{r} / \mathrm{min}$, i.e., the flow measurements were validated based on this rotation.

Rotation was varied by turning the motorcycle handles three times to accelerate the engine manually from zero to maximum speed. The test was monitored for $600 \mathrm{~s}$ and the engine cooling time determined during the tests was set for $2 \mathrm{~h}$, using an industrial fan. Three tests were performed on a new original oil pump and another three on a pump that had operated for $80,000 \mathrm{~km}$. The resulting graphs represent the average of each group of three tests.

\section{Thermal analysis of the composite materials}

Parameters such as temperature and frequency affect the performance of composites. A range of temperatures is usually considered in the design of several advanced structures; hence, it is essential to know if and at what temperature heat-related degradation occurs. It is also important to consider the frequency, in view of the influence of vibration on the performance of polymers. ${ }^{22}$ Thermogravimetry is a powerful tool to analyze thermal degradations in a wide range of temperatures, and the combined influence of temperature and frequency can be determined based on dynamic mechanical analysis (DMA). ${ }^{23}$

Dynamic mechanical measurements were taken with the equipment DMS 6100 model EXSTAR 6000 of SII Nanotechnology Inc., at the Department of Materials and Technology of Guaratinguetá Engineering Faculty, UNESP. The measurements were taken in a temperature range of $25^{\circ} \mathrm{C}$ to $270^{\circ} \mathrm{C}$ (at a heating rate of $3.0^{\circ} \mathrm{C} / \mathrm{min}$ ), and at different frequencies, which were determined based on calculated rotations in neutral, medium and high gear (10, 50 and $100 \mathrm{~Hz}$, respectively).

A three-point bending test with a $40.0-\mathrm{mm}$ span between supports was selected as the preferred testing geometry, since clamped boundaries affect damping

Table 2. Properties of the composites subjected to FEA analysis. ${ }^{18,20,24}$

\begin{tabular}{clll}
\hline Composite & Property & Unit & Value \\
\hline PPA + GF & $\begin{array}{l}\text { Poisson ratio } \\
\text { Parallel thermal } \\
\text { expansion } \\
\text { coefficient } \\
\text { Normal thermal } \\
\text { expansion } \\
\text { coefficient }\end{array}$ & $\begin{array}{l}{ }^{\circ} \mathrm{C}^{-1} \\
{ }^{\circ} \mathrm{C}^{-1}\end{array}$ & 0.39 \\
PPA + GF & $\begin{array}{l}\text { Poisson ratio } \\
+ \text { PTFE }\end{array}$ & $\begin{array}{l}\text { Parallel thermal } \\
\text { expansion } \\
\text { coefficient }\end{array}$ & $0.15 \times 10^{-4}$ \\
& $\begin{array}{c}{ }^{\circ} \mathrm{C}^{-1} \\
\text { Normal thermal } \\
\text { expansion } \\
\text { coefficient }\end{array}$ & $0.10^{-4}$ \\
& ${ }^{\circ} \mathrm{C}^{-1}$ & $0.11 \times 10^{-4}$ \\
\hline
\end{tabular}

PPA: polyphthalamide; GF: glass-fiber; PTFE: polytetrafluoroethylene.

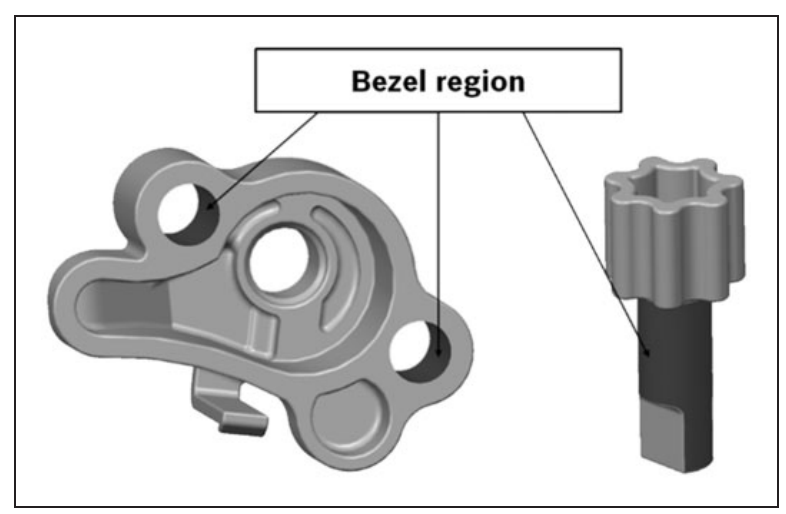

Figure 2. Details of the bezels (shadows) locking all the degrees of freedom in the holes (housing) and in the cylindrical body (shaft). 
measurements. All the dynamic tests were carried out in sinusoidal strain-controlled mode. During the measurements, a strain amplitude of $10 \mu \mathrm{m}$ was used to record the viscoelastic parameters. Composites specimens were

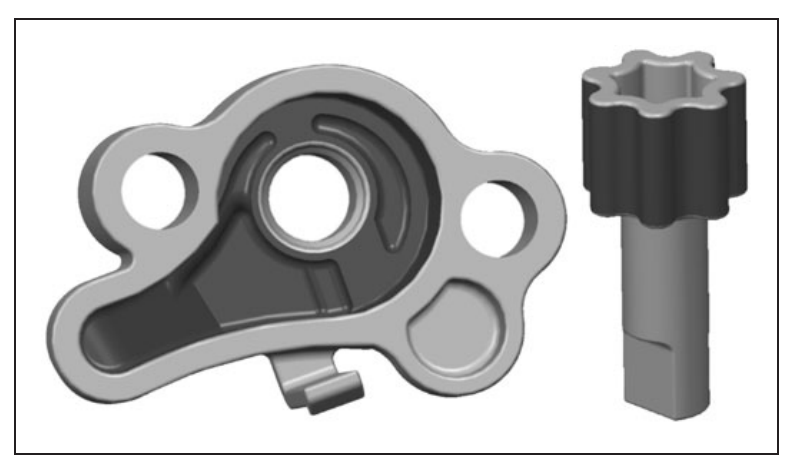

Figure 3. Details of the pressure applied on the surface (darker) of the housing and the inner gerotor. pre-stressed with an applied force of $10 \mathrm{~N}$ and a force track rating of $150 \%$. Samples were obtained from molded laminated plates, and the tests were conducted on both GF/PPA-PTFE and GF/PPA composites (Table 1).

Thermogravimetric analyses (TGA) were performed on a NETZSCH TGA 209 F1 Phoenix ${ }^{\circledR}$ thermobalance at the Schaeffler Brazil Group. The analyses were performed in the range of $20^{\circ} \mathrm{C}$ to $800^{\circ} \mathrm{C}$, applying a heating rate of $10^{\circ} \mathrm{C} / \mathrm{min}$, as described by Pini et al., ${ }^{10}$ in a nitrogen atmosphere. This procedure consisted of heating $25 \mathrm{mg}$ of each composite on a thermobalance and recording the change in weight resulting from heat and/ or other forms of degradation.

\section{Finite element analysis of the proposed model}

Among the results of the DMA, the minimum storage modulus $\left(\mathrm{E}^{\prime}\right)$ values of each composite were used as the elastic moduli (E) in the finite element analysis (FEA).

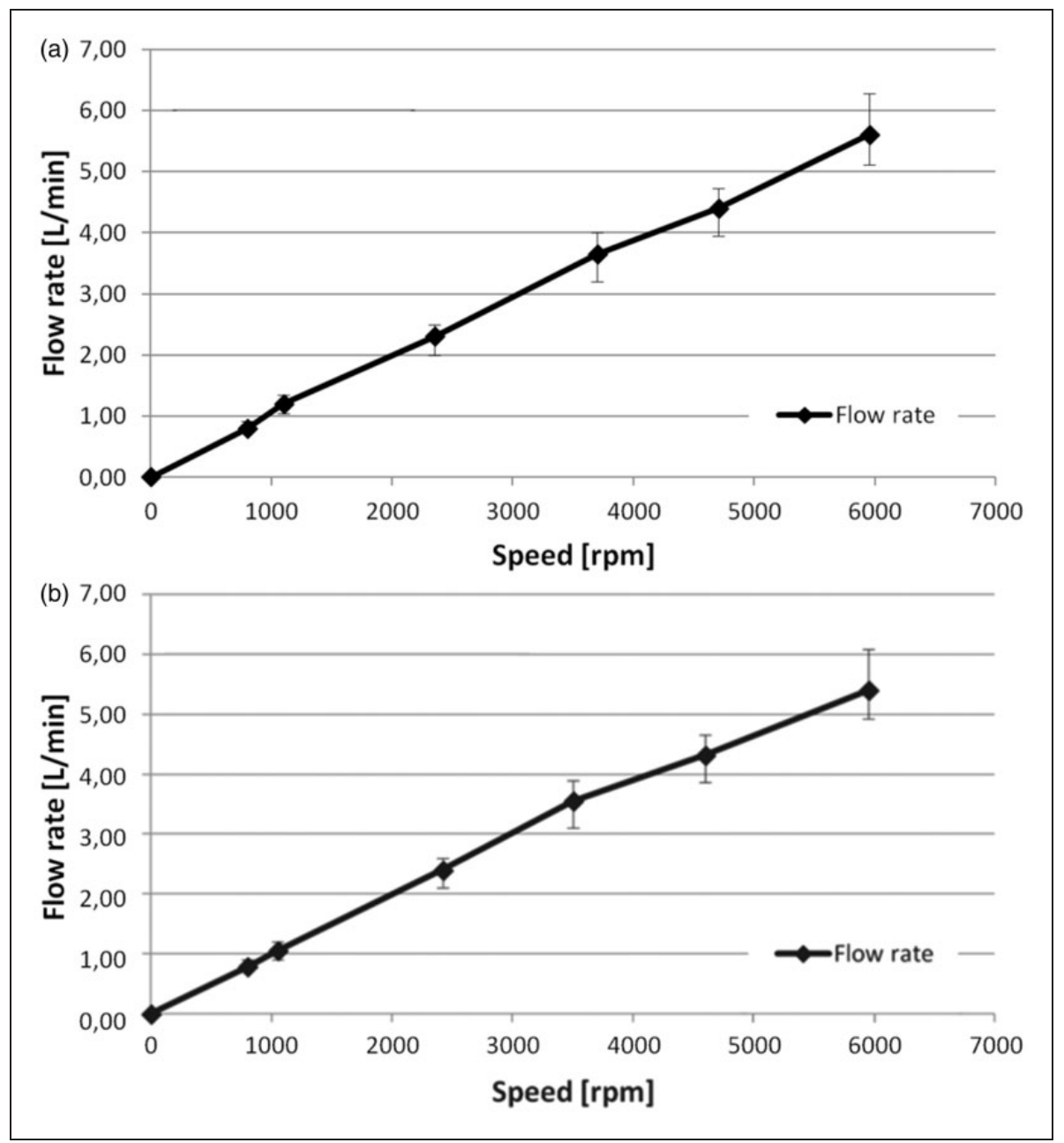

Figure 4. Oil flow rate as a function of rotation: (a) new original oil pump and (b) original pump after $80,000 \mathrm{~km}$. 
The minimum $\mathrm{Tg}$ obtained was $20^{\circ} \mathrm{C}$ above the highest temperature obtained in the performance test on the current oil pump, and this difference was considered to meet safety requirements. An internal pressure of 3 bar $(0.3 \mathrm{MPa})$ in the pump was also considered, using a safety factor of at least 1.6 times the maximum pressure obtained in the determination of the pump performance.

The new components were mathematically modeled using Pro/ENGINEER Wildfire 2.0 software, based on the current geometry, whose dimensions were determined using a PRISMO Navigator 7 3D measuring machine from ZEISS. The mathematically modeled new product was then analyzed by the finite element method-FEA, using PTC Pro/Mechanica software integrated with Pro/ENGINEER Wildfire 2.0.

The values of the properties of some of the composites were taken from datasheets and are presented in Table 2. These values were entered into the software, as was the storage modulus at $\mathrm{Tg}$ (obtained in the DMA).

Figure 2 shows the bezels in the region of the screw holes, which lock all the degrees of freedom (DoF) in the $\mathrm{x}, \mathrm{y}$ and $\mathrm{z}$ axes, while Figure 3 illustrates the surfaces where pressure was applied. The function of these bezels is to simulate the component under the action of the screws. In the outer gerotor, the bezel covers is its entire external diameter.

All the parts that were studied to determine the feasibility of using substitute materials were analyzed by FEA. However, as observed during the pump performance tests, the housing and inner gerotor/shaft are the most critical parts among the items studied for the use of substitute materials. All the pressure is applied on the housing, which also supports the other components, while the inner gerotor/shaft is subjected to torque and pressure and is also subject to more severe wear conditions. Only static pressure is applied to the outer

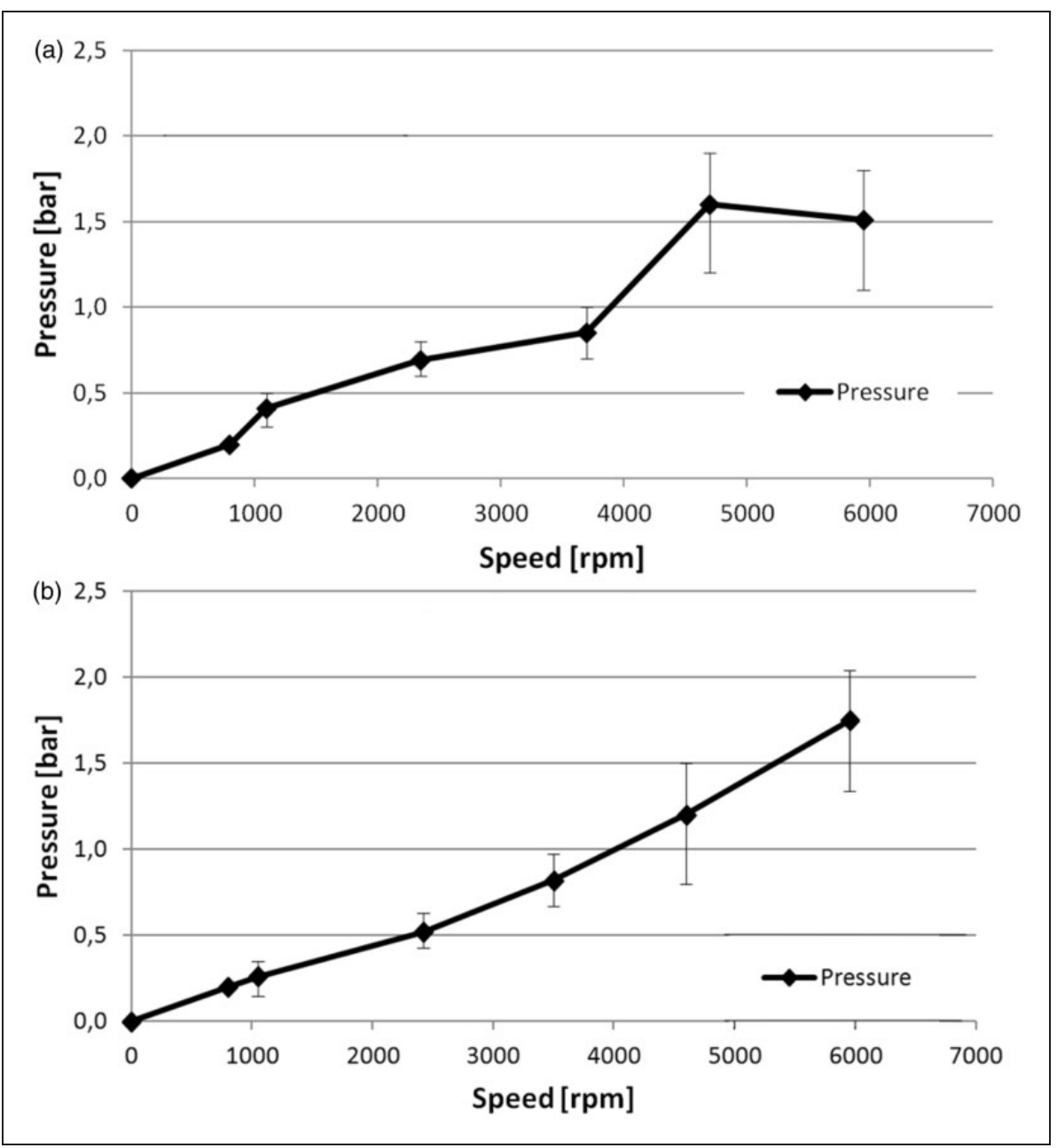

Figure 5. Pressure as a function of rotation: (a) new original oil pump and (b) original pump after $80,000 \mathrm{~km}$. 
gerotor (in its inner surface) and its minimal thickness is analytically calculated.

The von Mises stress (given in MPa) was calculated to verify if the proposed materials can withstand the stresses to which the parts are subjected.

\section{Results and discussion}

\section{Determining the performance of the current} oil pump

Figures 4 and 5 illustrate the results of the performance test (flow rate and pressure, respectively, as a function of rotation) of a new original oil pump (Figures 4(a) and 5(a)) and of an original pump after reaching $80,000 \mathrm{~km}$ (Figures 4(b) and 5(b)). Figure 6 shows the relationship between temperature and rotation for a new oil pump and a used one $(80,000 \mathrm{~km})$.

In Figures 4 to 6 , note that the highest pressure attained during the test of the new pump was about 1.6 bar (Figure 5(a)). The highest peak operating temperature was $88^{\circ} \mathrm{C}$ (Figure 6), which was reached at a working pressure of $1.5 \mathrm{bar}$ (Figure 6(a)). The flow/rotation relationship approached its maximum amplitude at $6000 \mathrm{r} / \mathrm{min}$, reaching a maximum flow of $5.6 \mathrm{~L} / \mathrm{min}$ (Figure 4(a)).

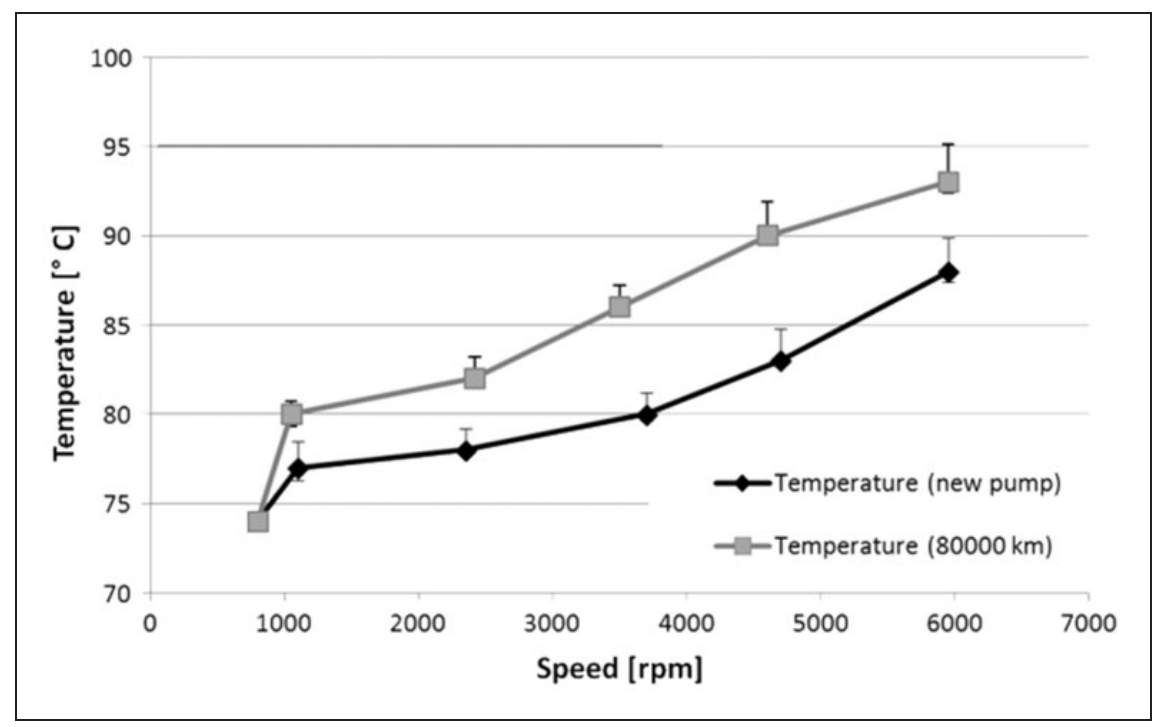

Figure 6. Temperature as a function of rotation: new original oil pump, and original pump after $80,000 \mathrm{~km}$.

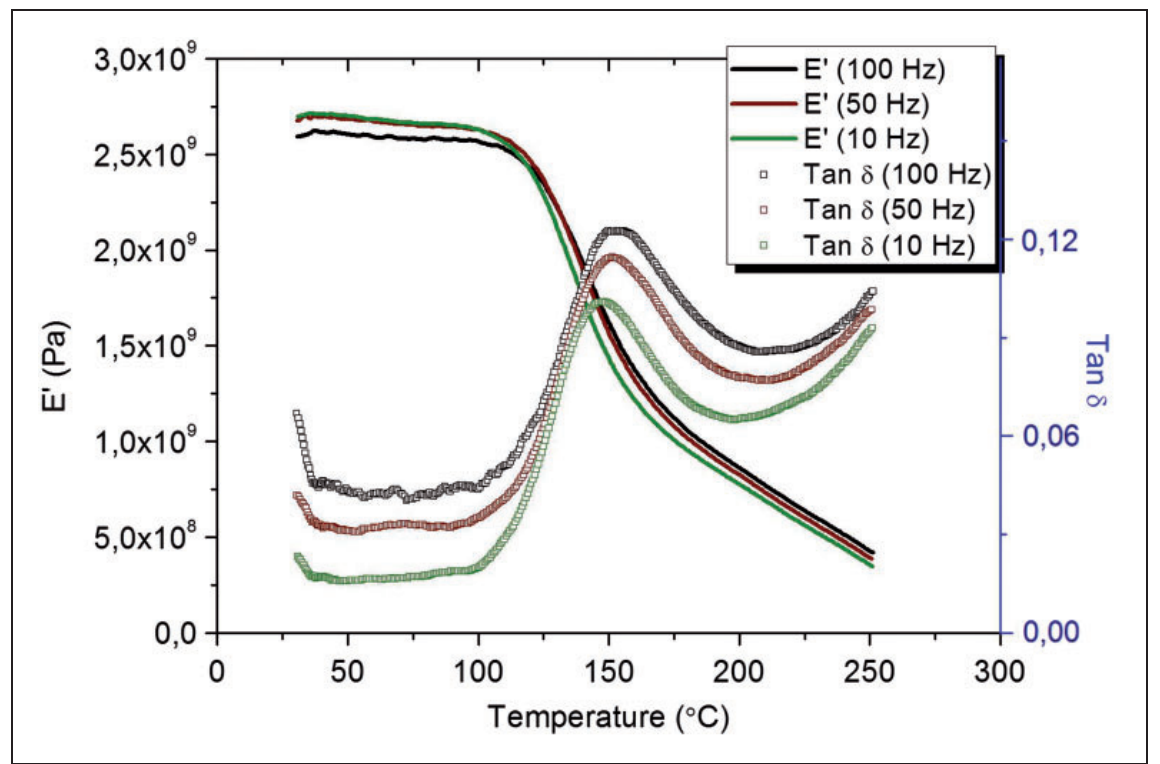

Figure 7. DMA curves of the glass-fiber/polyphthalamide composite at frequencies of 10,50 and $100 \mathrm{~Hz}$. 


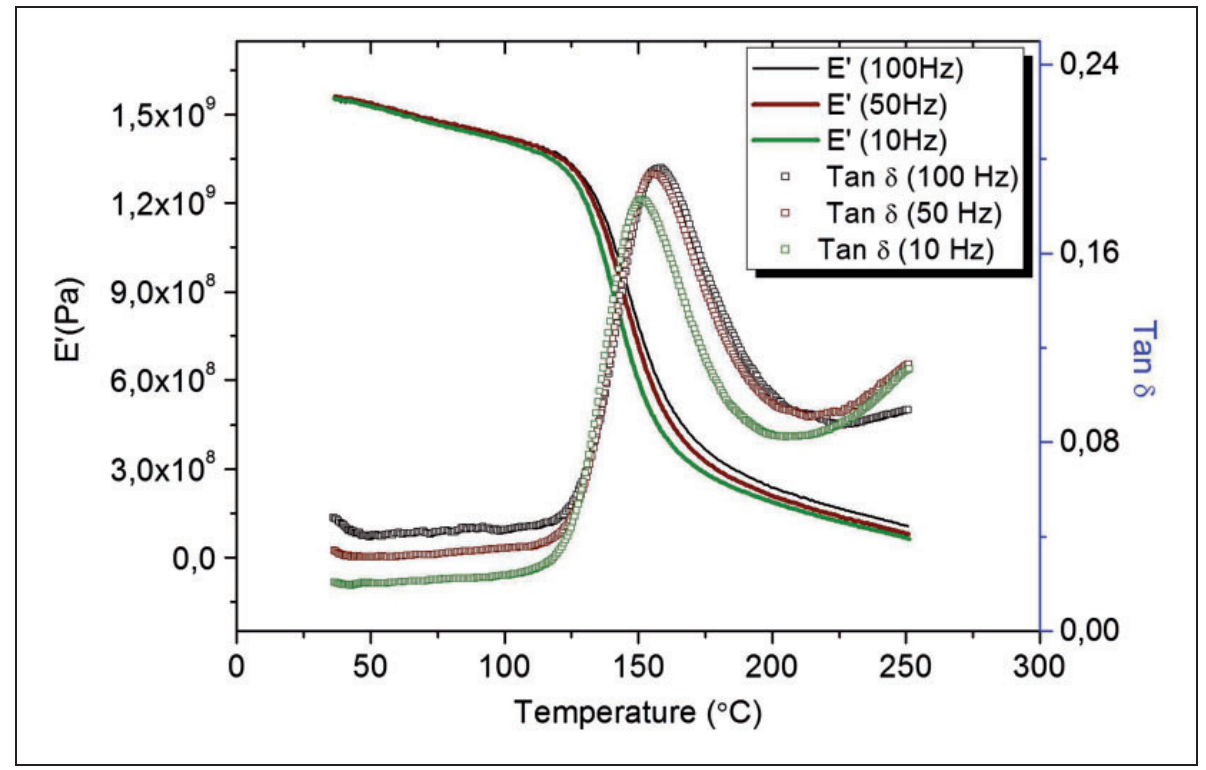

Figure 8. DMA curves of the glass-fiber/polyphthalamide/PTFE composite at frequencies of 10,50 and $100 \mathrm{~Hz}$.

In Figure 4(b), note that the used oil pump showed similar flow/rotation behavior than the new pump. In both cases, this is explained by the change in the flow regime due to the gerotor profile. Nevertheless, a $5.4 \mathrm{-L} / \mathrm{min}$ flow was achieved at around $6000 \mathrm{r} / \mathrm{min}$, confirming that even after undergoing wear, the oil pump components showed almost no loss in efficiency. However, due to wear, the gaps were enlarged, thus reducing the average operating pressure. The average operating pressure in the used pump was found to be 1.35 bar, which is $10 \%$ lower than that of a new pump. These values were recorded by the software at the end of the test.

The operating temperature of the used pump reached $93^{\circ} \mathrm{C}$ (Figure 6), at which point the pressure reached the maximum of $1.8 \mathrm{MPa}$ (Figure 5(b)). These values represent the maximum ones reached by the two pumps during the test and will be considered in studies of the proposed substitute materials. The safety coefficients used here were more than adequate to include variations shown by the standard deviations of the mean results (see item FEA for proposed model).

A study similar to the presented results in Figures 4 to 6 is required for motorcycle oil pump designs, without considering the materials employed, and subsequent studies are useful to verify the feasibility of using substitute materials.

\section{Thermal analysis of the composite materials}

Figures 7 and 8 illustrate the dynamic mechanical thermal analysis curves of samples of composite materials chosen for the housing (PPA $+35 \%$ GF) and that selected for gerotors (PPA $+30 \%$ GF $+14 \%$ PTFE),
Table 3. DMA parameters of the glass-fiber/polyphthalamide and glass-fiber/polyphthalamide/PTFE composites at 10,50 and $100 \mathrm{~Hz}$.

\begin{tabular}{lllll}
\hline Material & Figure & $\begin{array}{l}\text { Frequency } \\
(\mathrm{Hz})\end{array}$ & $\begin{array}{l}\text { Storage } \\
\text { module } \\
\text { at } \mathrm{Tg}(\mathrm{GPa})\end{array}$ & $\begin{array}{l}\mathrm{Tg} \\
\left({ }^{\circ} \mathrm{C}\right)\end{array}$ \\
\hline $\mathrm{PPA}+35 \%$ GF & 7 & 10 & 2.5 & 121 \\
& & 50 & 2.6 & 119 \\
$\mathrm{PPA}+30 \%$ & 8 & 100 & 2.6 & 113 \\
$\mathrm{GF}+14 \%$ PTFE & & 10 & 1.33 & 127 \\
& & 100 & 1.31 & 131 \\
& & 1.32 & 133 \\
\hline
\end{tabular}

PPA: polyphthalamide; GF: glass-fiber; PTFE: polytetrafluoroethylene.

respectively (see Table 1). The $\mathrm{E}^{\prime}$ curves clearly show the limit between glassy and rubbery regions, characterized by the decreasing $\mathrm{E}^{\prime}$ values of both materials. Table 3 lists the storage modulus $\left(\mathrm{E}^{\prime}\right)$ values at the glass transition temperature $(\mathrm{Tg})$ at three frequencies $(10,50$ and $100 \mathrm{~Hz})$, as well as the glass transition temperatures, considering the point at which the $\mathrm{E}^{\prime}$ drops as coincident with the glass transition ( $\mathrm{Tg})$, since it is associated with the increase in molecular chain mobility. This approach is conservative, because it gives a lower temperature than $\mathrm{Tg}$ obtained through $\tan \delta$ peak.

Figures 7 and 8 show the influence of frequency on the viscoelastic parameters of both materials: at higher frequencies, the $\mathrm{E}^{\prime}$ and $\tan \delta$ are shifted to the right, indicating that the material does not have sufficient 
time to relax, and that higher energy is required to trigger the transition event.

It is evident, however, that the addition of PTFE causes variations in the behavior of the material, which is a significant phenomenon, since there is a reduction in the $\mathrm{E}^{\prime}$ drop point in comparison to that of the composite without PTFE. This suggests that
PTFE improves chain mobility, anticipating the process of energy dissipation in the material.

With regard to $\tan \delta$, also plotted at 10,50 and $100 \mathrm{~Hz}$ along dotted lines in Figures 7 and 8, it is known that damping properties are related to the balance between the elastic and viscous phases in a polymeric structure. When fibers are used as reinforcement

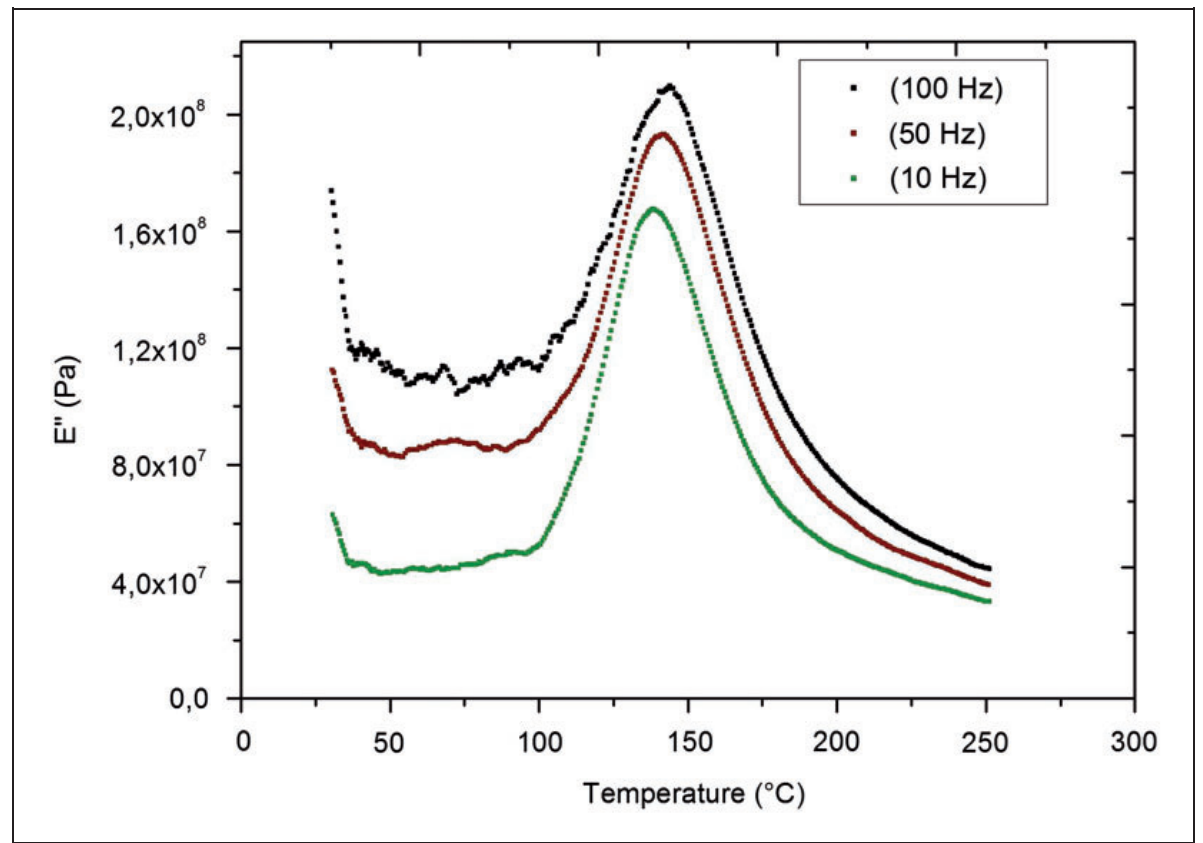

Figure 9. $E^{\prime \prime}$ curves of the glass-fiber/polyphthalamide composite at frequencies of 10,50 and $100 \mathrm{~Hz}$.

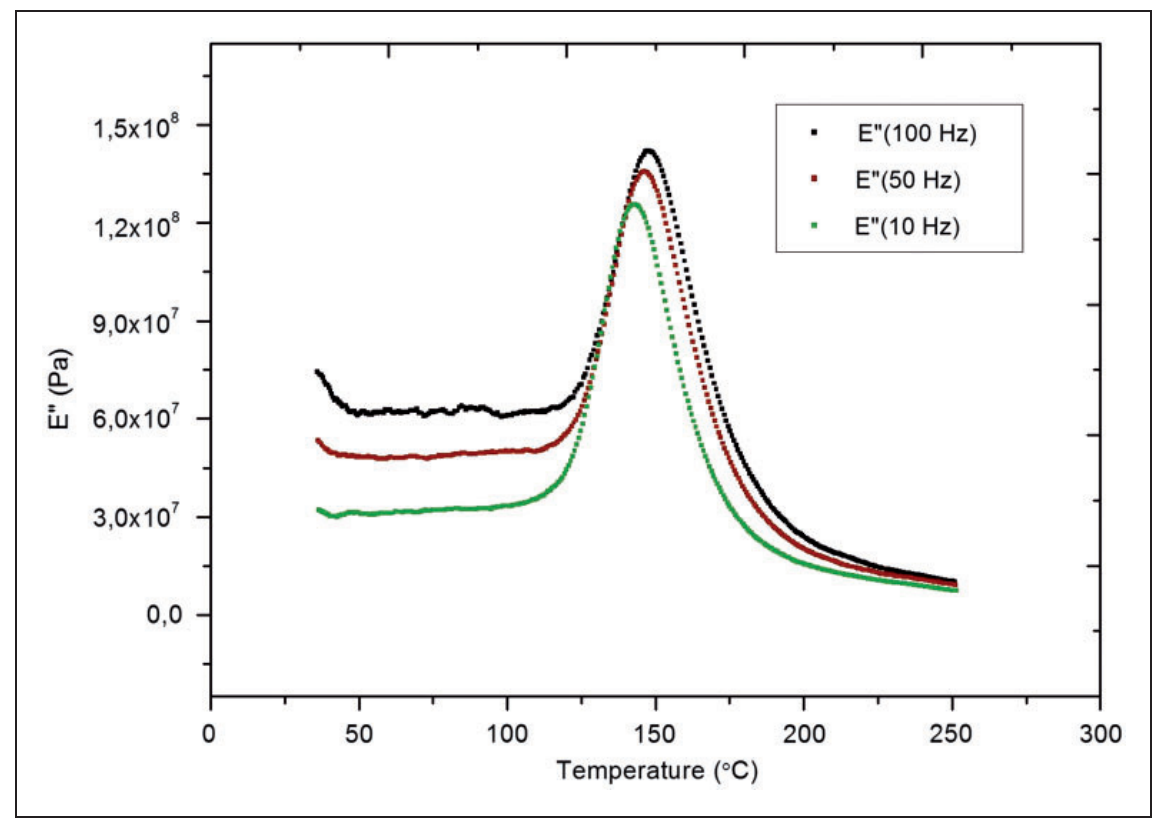

Figure 10. E" curves of the glass-fiber/polyphthalamide/PTFE composite at frequencies of 10,50 and $100 \mathrm{~Hz}$. 
and adhesion is good, chain mobility restriction is observed, which is reflected in the $\tan \delta$. A smaller area under the $\tan \delta$ peak indicates stronger interface adhesion. Therefore, although the PTFE enhanced the chain mobility, it was found to reduce adhesion at the fiber/matrix interface.

As it was already commented, it was also found that, in both cases, the storage modulus values increased in response to increasing frequencies at a given temperature (isothermal conditions). This is explained by the polymer chains, which absorb energy in given frequency ranges, a phenomenon that occurs only when the frequency is equal to the relaxation time.

This relaxation time, which tends to decrease with decreasing temperature, indicates that chain mobility is related to the molecular structure of the material and to temperature. Relaxation is generally associated with conformational changes, and the effect of this condition as a consequence of the temperature and frequency relationship indicates that, at high frequencies or long relaxation times, the behavior of the polymer is glassy, with a higher storage modulus. ${ }^{25}$ PTFE influences the storage modulus, favoring polymer chain mobility.

Table 4. Main results of the thermogravimetric measurements of the two composites under study.

\begin{tabular}{lll}
\hline Material & $\begin{array}{l}\text { Loss mass } \\
\text { at } 100^{\circ} \mathrm{C}(\%)\end{array}$ & $\begin{array}{l}\text { Residual mass } \\
\text { at } 650^{\circ} \mathrm{C}(\%)\end{array}$ \\
\hline $\mathrm{PPA}+35 \% \mathrm{GF}$ & 1.57 & 32.91 \\
$\mathrm{PPA}+30 \% \mathrm{GF}+14 \% \mathrm{PTFE}$ & 1.89 & 27.99 \\
\hline
\end{tabular}

PPA: polyphthalamide; GF: glass-fiber; PTFE: polytetrafluoroethylene.
Table 3 also lists the $\mathrm{Tg}$ values at the point where the $\mathrm{E}^{\prime}$ drops at frequencies of 10,50 and $100 \mathrm{~Hz}$, which were always higher (at least $20^{\circ} \mathrm{C}$ higher and at most $40^{\circ} \mathrm{C}$ higher) than the maximum working temperature reached in the oil pump performance test $\left(93^{\circ} \mathrm{C}\right.$, Figure 6). This suggests that the composites are suitable for operating conditions at these frequencies.

Figures 9 and 10 show the viscous response of the GF/PPA and GF/PPA/PTFE composites, respectively, based on their $\mathrm{E}^{\prime \prime}$ curves. These curves represent energy dissipation measurements, and their height is related to the relaxation process: higher $E^{\prime \prime}$ values, i.e., higher peaks, indicate greater energy dissipation. In composites, this is attributed to the increase in internal friction, and in this study, the composite containing PTFE presented a lower value of $\mathrm{E}^{\prime \prime}$, which means that lower energy was needed to cause this dissipation.

Table 4 shows the main results of the thermogravimetric tests carried out on the GF/PPA and GF/PPA/ PTFE composites.

As can be seen in Table 4, the composites selected for the housing (PPA/glass) and gerotors (PPA/GF/PTFE) can be considered very stable, since the materials maintained more than $98 \%$ of their original mass at $100^{\circ} \mathrm{C}$. This negligible mass loss is likely attributable to loss of moisture.

At $650^{\circ} \mathrm{C}$, the GF/PPA composite contained a nonvolatilized fraction (considered inorganic) of about $33 \%$, while that of the GF/PPA/PTFE composite was $28 \%$. These fractions are very close to the $35 \%$ and $30 \%$ GF contents reported by the manufacturer. ${ }^{17,18}$ Between $500^{\circ} \mathrm{C}$ and $600^{\circ} \mathrm{C}$, the composite selected for the gerotors also showed an intermediate mass loss of $13.69 \%$, probably corresponding to the PTFE.

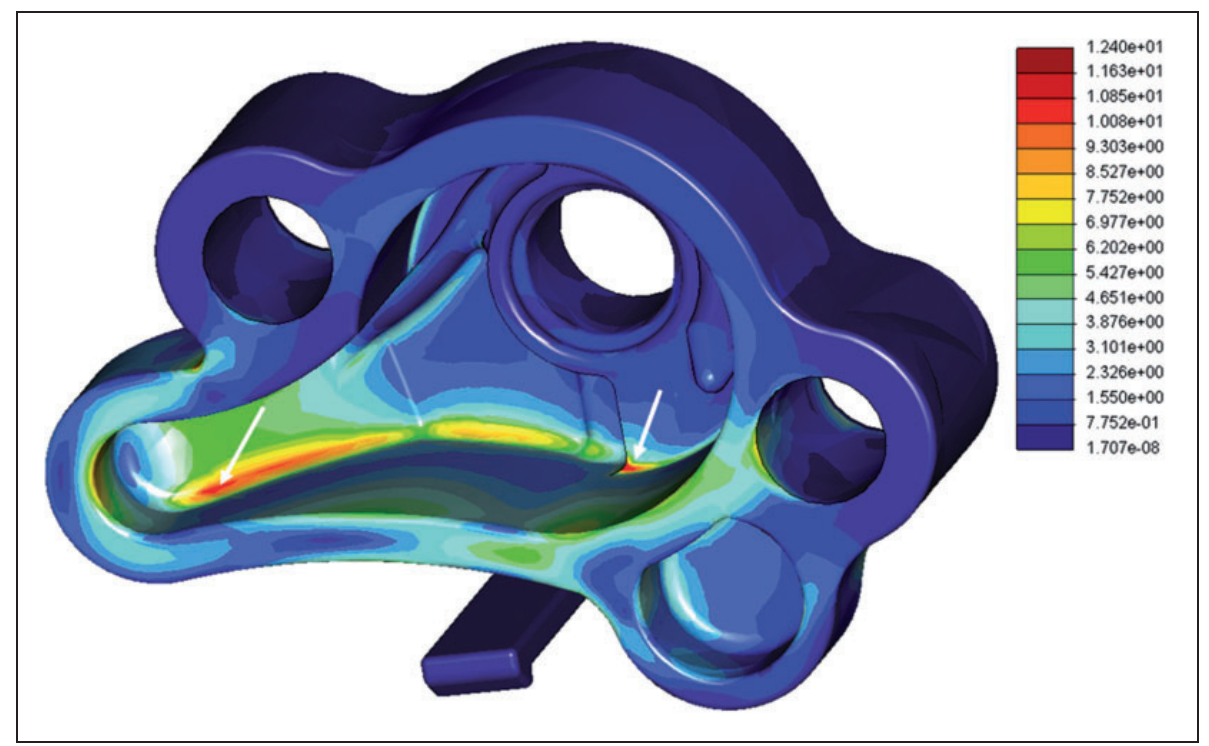

Figure I I. FEA analysis of the housing: von Mises stress ( $\mathrm{MPa})$. 


\section{FEA of the proposed model}

The maximum pressure (1.8 bar for the used pumpFigure 5(b)) determined in the performance tests of the current pump was multiplied by a safety factor of at least 1.6 to provide the value of 3 bar (or $0.3 \mathrm{MPa}$ ), which was used in the FEA of the proposed model. The minimum storage modulus $\left(\mathrm{E}^{\prime}\right)$ values of each composite
(2.5 GPa for PPA $+\mathrm{GF}$ and $1.31 \mathrm{GPa}$ for PPA $+\mathrm{GF}$ + PTFE, respectively - see Table 3) were used as the elastic modulus (E) in the FEA. As mentioned before, the minimum $\mathrm{Tg}$ obtained $\left(113^{\circ} \mathrm{C}\right.$, Table 3$)$ was $20^{\circ} \mathrm{C}$ above the highest temperature obtained in the performance test $\left(93^{\circ} \mathrm{C}\right.$, Figure 6) on the current oil pump and this difference was considered to meet safety requirements.

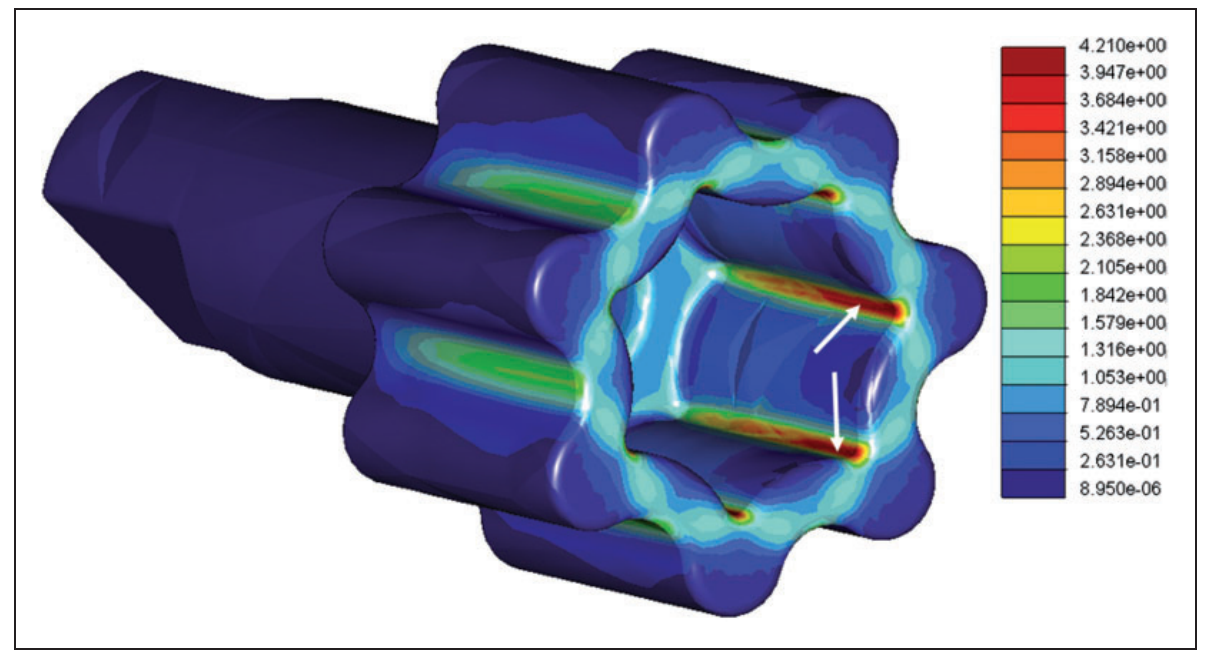

Figure 12. FEA analysis of the integrated shaft/inner gerotor: von Mises stress (MPa).

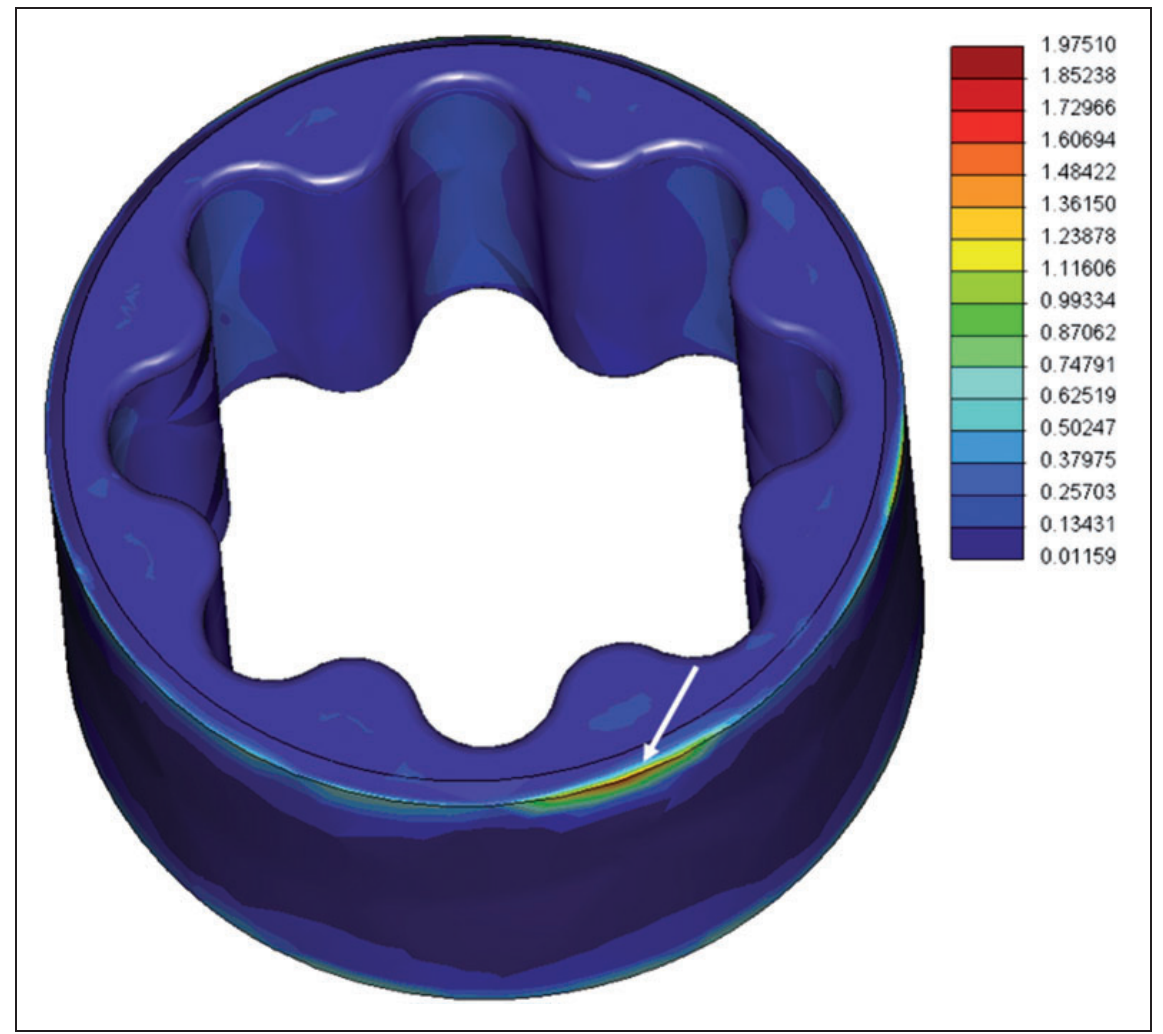

Figure 13. FEA analysis of the outer gerotor: von Mises stress (MPa). 
Figures 11 to 13, respectively, show the FEA results of von Mises stresses in the housing, in the shaft integrated with the inner gerotor and in the outer gerotor. In figures, the highest von Mises stresses are indicated by arrows.

In Figures 11 to 13, note that the highest von Mises stresses (indicated by arrows) found for the housing, the shaft integrated with the inner gerotor and the outer gerotor were 12,4 and $1.5 \mathrm{MPa}$, respectively. According to the manufacturer, based on stress versus strain curves recorded at various temperatures, the composite materials withstand stresses of $80 \mathrm{MPa}$ at $100^{\circ} \mathrm{C}$ (temperature above the maximum working temperature considered-Figure 6). ${ }^{18-20,24}$ This means that the safety factor of the proposed substitute materials is almost 7 for the housing, while that of the integrated shaft/inner gerotor is approximately 20 , and that of the outer gerotor is more than 50 .

The FEA analysis revealed a displacement of almost zero in the outer gerotor and in the shaft/inner gerotor: 0.00092 and $0.00813 \mathrm{~mm}$, respectively. The maximum displacement measured in the housing was $0.17664 \mathrm{~mm}$, which was considered acceptable.

These results, albeit interesting, do not provide conclusive evidence of the feasibility of using these composites for some of the oil pump parts in $150 \mathrm{cc}$ motorcycles. Additional tests are needed, including tests of longer duration on the current pumps, as well as creep and aging tests of the composite materials and prototype performance tests (to obtain curves such as those shown in Figures 4 to 6 ).

\section{Conclusions}

The results of this feasibility study suggest that motorcycle oil pump parts can be manufactured with composite materials, i.e., housing made of PPA/GF composite, and outer gerotor and integrated shaft (inner gerotor and shaft) made of PPA/GF/PTFE composite.

The maximum operating temperature (below $93^{\circ} \mathrm{C}$ ) did not cause significant mass loss of the proposed materials and proved to be lower than the glass transition temperature of the polymers in question determined under dynamic conditions (the minimum $\mathrm{Tg}$ obtained was $113^{\circ} \mathrm{C}$ ). These results suggest that the mechanical properties of the composites remain unchanged below the maximum operating temperature. The FEA indicated that the stresses generated in the parts were much lower than those the materials can withstand, i.e., almost 7 times lower in the housing, about 20 times lower in the integrated shaft/inner gerotor and more than 50 times lower in the outer gerotor, considering the mechanical performance of these parts at the maximum operating temperature.

\section{Aknowledgements}

The authors are indebted to the Schaeffler Group, FaÇ bio Renato Sirbone and Danilo Claudio de Godoy for their support.

\section{Declaration of Conflicting Interests}

The author(s) declared no potential conflicts of interest with respect to the research, authorship, and/or publication of this article.

\section{Funding}

The author(s) received no financial support for the research, authorship, and/or publication of this article.

\section{References}

1. Farag MM. Quantitative methods of materials substitution: application to automotive components. Mater Design 2008; 29: 374-380.

2. Duan S, Yang X and Tao Y. Experimental study on strain rate-dependent behaviour and failure modes of long glass fiber-reinforced polypropylene composite. J Reinf Plas Comp 2015; 34: 1261-1270.

3. Santos Neto AO, Mancini SD and Sirbone FRC. Production of an axial piston: impacts resulting from the substitution of steel by a polymer-based material. J Clean Prod 2013; 46: 36-41.

4. Basshuysen RV and Schafer F. Internal combustion engine - handbook. 1st ed. New York: SAE International and Professional Engineering Publishing, 2004, p. 868.

5. Linsingen IV. Fundamentos de Sistemas Hidráulicos [Hydraulic systems]. 4th ed. Florianópolis: EdUFSC, 2013, p. 399.

6. Zimermann MA. Sistema especialista protótipo para auxílio na seleção de bombas hidrostáticas [Prototype to aid hydrostatic pumps selection]. Master Dissertation, Federal University of Santa Catarina, Florianópolis, https://repositorio.ufsc.br/xmlui/bitstream/handle/ $123456789 / 86222 / 209363$.pdf?sequence $=1 \&$ isAllowed $=y$ (2003, accessed 7 September 2016).

7. Gamez-Montero PJ and Maciá EC. Fluid dynamics behaviour of an internal Rotary pump generated by trochoidal profiles. In: Proceedings of 1st fluid power net international symposium, Hamburg, pp.33-47. West Lafayette: FPNI, http://citeseerx.ist.psu.edu/viewdoc/ download?doi=10.1.1.194.9403\&rep=rep1\&type $=$ pdf (2000, accessed 2 September 2016).

8. Jung SY, Bae JH, Kim MS, et al. Development of a new gerotor for oil pumps with multiple profiles. Int $J$ Precis Eng Man 2011; 12: 835-841.

9. Cousin T, Galy J and Dupuy J. Molecular modelling of polyphthalamides thermal properties: Comparison between modelling and experimental results. Polymer 2012; 53: 3203-3210.

10. Park J, Goh M and Akagi K. Helical nylons and polyphthalamides synthesized by Chiral interfacial polymerizations between Chiral nematic liquid crystal and water layers. Macromolecules 2014; 47: 2784-2795. 
11. Pini N, Zaniboni C, Busato S, et al. Perspectives for reactive molding of PPA as matrix for high-performance composite materials. J Thermoplas Compos 2006; 19: 207-216.

12. Joannès S, Mazé L and Bunsell AR. A concentrationdependent diffusion coefficient model for water sorption in composite. Compos Struct 2014; 108: 111-118.

13. Russo P and Acierno D. Improving the creep resistance for engineering thermoplastic materials. Int J Mater Form 2008; 1: 649-652.

14. Cao L, Deng S, He Z, et al. Effects of carbon nanotube on mechanical, crystallization, and electrical properties of binary blends of poly(phenylene sulfide) and polyphthalamide. J Therm Anal Calorim 2016; 125: 927-934.

15. Li J. The effect of PTFE on the mechanical and friction and wear properties of GF/PA6 composites. Adv Mat Res 2011; 284-286: 2370-2373.

16. Reinicke R, Haupert F and Friedrich K. On the tribological behaviour of selected, injection moulded thermoplastic composites. Compos A Appl S 1998; 29A: $763-771$.

17. Yang Y-K, Tzeng C-J, Yang R-T, et al. Study on tribological behaviors of short glass fiber and polytetrafluoroethylene reinforced polycarbonate composites via a d-optimal mixture design. Polym Advan Technol 2000; 22: 2191-2000.

18. DuPont. Product Information: Zytel ${ }^{\circledR}$ HTNWRF51G30 NC010, http://www.campusplastics.com/campus/en/data sheet/Zytel.\%C2.\%AE + HTN51G35HSL + NC010/ DuPont + Engineering + Polymers/52/f3d52506 (2005, accessed 2 September 2016).

19. Santos Neto AO and Mancini SD. Caracterização de Aspectos Tribológicos da Poliftalamida - PPA Utilizando o Método de Esfera sobre Placa [Characterization of tribological aspects of poly (phthalamide) - PPA, using the sphere on flat method]. In:
Proceedings of the 10th Brazilian congress of polymers, Foz do Iguaçu, 13-17 October 2009, pp. 1-8. São Carlos-Brazil: ABPol, https://www.ipen.br/biblioteca/cd/cbpol/2009/PDF/803.PDF (accessed 25 August 2016).

20. DuPont. Product Information: Zytel ${ }^{\circledR}$ HTN51G35HSLR BK420, http://www.campusplastics.com/campus/de/data sheet/Zytel.\%C2.\%AE + HTN51G35HSLR + BK420/ DuPont + Engineering + Polymers/52/8f98ce40 (2009, accessed 2 September 2016).

21. Iudicello F and Mitchell D. CFD modelling of the flow in a gerotor pump. In: Burrows CR and Edge KA (eds) PTMC 2002, 1st ed. Bath: University of Bath, 2002, pp.53-66.

22. Melo JD and Radford DW. Time and temperature dependence of the viscoelastic properties of CFRP by dynamic mechanical analysis. Compos Struct 2005; 70: 240-253.

23. Canevarolo Junior SV. Análise Térmica DinâmicoMecânica [Dynamic mechanical analysis]. In: Canevarolo Junior SV (ed.) Técnicas de Caracterização de Polímeros [Polymer characterization techniques], 1st ed. São Paulo: Art Liber, 2004, pp.78-89.

24. Santos Neto AO. Avaliação do desempenho de compósitos de PPA/Fibra de vidro para aplicação em bombas de óleo de motores de motocicletas [Evaluation of the performance of PPA/Fiber glass composites for oil pump motorcycles engines application]. Master Dissertation, São Paulo State University, São Paulo, http://base.repositorio.unesp.br/handle/11449/99738 (2010, accessed 8 September 2016).

25. Cassu SN and Felisberti MI. Comportamento Dinâmicomecânico e relaxações em polímeros e blendas poliméricas [Dynamic mechanical behavior and relaxations in polymers and polymeric blends]. Quim Nova 2005; 28 : 255-263. 